\title{
Experience of switching to NovoEight: views of people with haemophilia
}

Debra Pollard, Kate Khair, Mike Holland

Management of haemophilia A requires administration of factor VIII therapy which, for those with severe haemophilia $A$ in the UK, is predominantly selfadministered at home in a prophylactic regimen to prevent or minimise bleeding. The UK undertakes a national tendering process every three years to ensure access to current and new therapies at a cost-effective price, through contracting for large volumes from individual suppliers. This means that some products may no longer be available and that new products can enter the UK market at any tendering stage.

In the latest tendering round, in 2018, more than one product was withdrawn from the UK market and a new product (NovoEight ${ }^{\circledR}$; Novo Nordisk) was added to the prescribing list. This meant people with haemophilia having to change products. The experience of 77 people with haemophilia or their carers who changed treatment products during this process was captured by questionnaires administered by haemophilia nurses from 12 treatment centres. Overall, although people with haemophilia felt that they had little influence in decision making about changing to NovoEight, they were confident with their new treatment including

DEBRA POLLARD

Katharine Dormandy Haemophilia \& Thrombosis Centre,

Royal Free Hospital, London, UK.

Email: Debra.Pollardanhs.net

KATE KHAIR

Haemnet, London, UK

MIKE HOLLAND

Haemnet, London, UK

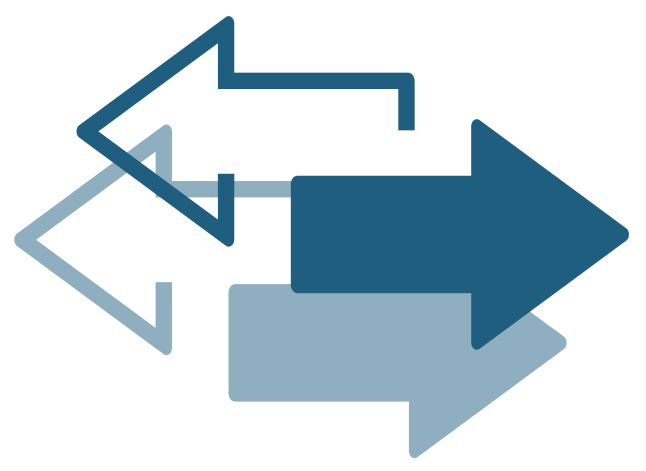

A survey of people with haemophilia in the UK whose factor product was switched to NovoEight found that although most felt they had little influence on the decision to switch, the majority continued to have confidence in the new treatment

packaging and accessories for administration. This was seen more in those who switched from plasma-derived products where ease of infusion was rated highly. Users' views of haemophilia treatment should be collected at times of change to identify facilitators and barriers experienced in self-management

Keywords: NovoEight, switching treatment, haemophilia, patient experience, people with haemophilia - views

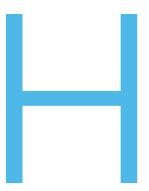

aemophilia is a long-term inherited bleeding disorder. People with haemophilia A are either missing or have reduced levels of factor VIII clotting factor protein. As a result, people with haemophilia A have a tendency to bleed for longer than most non-affected people and to bleed internally into joints, muscles or organs ${ }^{[1]}$. Those

This is an Open Access article distributed under the terms of the Creative Commons Attribution-NonCommercial-NoDerivs License (https://creativecommons.org/licenses/by-nc-nd/3.0/) which permits use and distribution in any medium, provided the original work is properly cited, the use is non-commercial, and no modifications or adaptations are made. Copyright is retained by the authors. 
with severe and moderate haemophilia require regular prophylactic treatment to prevent spontaneous bleeds, including joint bleeds that result in haemophilic arthropathy with associated disability, immobility and chronic pain. Those with mild haemophilia usually only require treatment following a traumatic injury or prior to surgery or invasive procedures.

In the UK, most people with haemophilia A are treated with replacement clotting factor concentrates produced by recombinant technologies. The widespread adoption of factor VIII prophylaxis over recent decades has highlighted haemophilia as an expensive condition to treat. The adoption in the UK of a national tender system for the purchasing of clotting factor concentrates has led to significant savings in the National Health Service (NHS) budget ${ }^{[2]}$.

As a result of the tendering process, patients may have to switch product, either because a previously used product is no longer available within the tender or in order for haemophilia centres to reach centrally set target volumes within a year of contract award.

In spring 2018, following a contract award, a new factor VIII product, turoctocog alfa (NovoEight ${ }^{\circledR}$; Novo Nordisk), entered the UK market and others were no longer available ${ }^{[3]}$. The authors took the opportunity to assess the additional workload imposed on haemophilia nurses ${ }^{[4]}$ and subsequently to survey patients for their opinions of the switch process and their satisfaction with the new product.

\section{METHODS}

Following the outcome of the 2018 national recombinant factor VIII tender, we undertook a series of semi-structured telephone interviews with 12 senior nurses from haemophilia centres across the UK ${ }^{[4]}$. In addition, we developed a short patient questionnaire that was administered by the UK haemophilia centre participants to a selection of patients who had been switched to NovoEight. The patients were identified by their haemophilia nurses, and every effort was made to contact all who had switched to ensure an unbiased selection. Participants had no further requirements beyond their response to the telephone questionnaire. This was deemed to be service evaluation and was registered as such at each participating centre, thus ethical approval was not required.

The questionnaire was administered by telephone and all results were analysed using RStudio, an open source software package developed for the R statistical computing environment. Descriptive statistics are used to describe the sample and to give information on the basic features of the data (e.g. mean, median, standard deviation); inferential statistics using standard statistical tests (Pearson's Chi-squared and Mann-Whitney tests) were used to look for correlations.

\section{RESULTS}

A total of 77 interviews were conducted with people with haemophilia or their caregiver who attended nine haemophilia centres across the UK. Table 1 summarises the characteristics of the responding population and shows that the mean time on previous medication is the same for adults and children. Five people with haemophilia switched from a plasmaderived product and 15 of the switches reflect product non-availability following the tender. However, most

Table 1: Patient characteristics

\begin{tabular}{|c|c|c|c|}
\hline & $\begin{array}{l}\text { ALL PARTICIPANTS } \\
(\mathrm{N}=77)\end{array}$ & $\begin{array}{l}\text { ADULTS AGED } 16+\text { YEARS } \\
(\mathrm{N}=63)\end{array}$ & $\begin{array}{l}\text { CAREGIVERS OF CHILDREN } \\
\text { AGED <16 YEARS } \\
(\mathrm{N}=14)\end{array}$ \\
\hline Severity & $\begin{array}{l}\text { Severe }(n=74) \\
\text { Moderate }(n=1) \\
\text { Mild }(n=2)\end{array}$ & $\begin{array}{l}\text { Severe }(n=60) \\
\text { Moderate }(n=1) \\
\text { Mild }(n=2)\end{array}$ & $\begin{array}{l}\text { Severe }(n=14) \\
\text { Moderate }(n=0) \\
\text { Mild }(n=0)\end{array}$ \\
\hline Treatment & $\begin{array}{l}\text { On demand }(n=4) \\
\text { Prophylaxis }(n=73)\end{array}$ & $\begin{array}{l}\text { On demand }(n=4) \\
\text { Prophylaxis }(n=59)\end{array}$ & $\begin{array}{l}\text { On demand }(n=0) \\
\text { Prophylaxis }(n=14)\end{array}$ \\
\hline Mean age at switch & & 31.57 years & 11.14 years \\
\hline Time on previous medication & & 7.28 years & 7.28 years \\
\hline Previous FVIII product & $\begin{array}{l}\text { ReFacto }(n=53) \\
\text { Helixate }(n=10) \\
\text { Kogenate }(n=5) \\
\text { Fanhdi }(n=4) \\
\text { Optivate }(n=1) \\
\text { unknown }(n=4)\end{array}$ & $\begin{array}{l}\text { ReFacto }(n=43) \\
\text { Helixate }(n=10) \\
\text { Kogenate }(n=4) \\
\text { Fanhdi }(n=4) \\
\text { Optivate }(n=0) \\
\text { unknown }(n=2)\end{array}$ & $\begin{array}{l}\text { ReFacto }(n=10) \\
\text { Helixate }(n=0) \\
\text { Kogenate }(n=1) \\
\text { Fanhdi }(n=0) \\
\text { Optivate }(n=1) \\
\text { unknown }(n=2)\end{array}$ \\
\hline
\end{tabular}


$(n=53)$ involved a switch from one recombinant product to another.

Most participants (73\%; 56/77) said that discussions regarding switching decisions had been with doctors. Most reported having discussions regarding switching decisions with the haemophilia multidisciplinary team (MDT); however, 16\% (12/77) indicated that they had only discussed switching product with a specialist nurse. Most participants felt they had little influence on the decision to switch to NovoEight (Figure 1). There was no statistically significant difference between adult patients and caregivers of children in this respect (Mann-Whitney test, $p=0.40$ ).

Most participants said they had used all of their old product prior to switching; just four adult patients had not done so. One fifth of participants $(19.7 \% ; 15 / 76)$

Figure 1: Participants' perceived level of influence over the decision to switch product

$$
30
$$

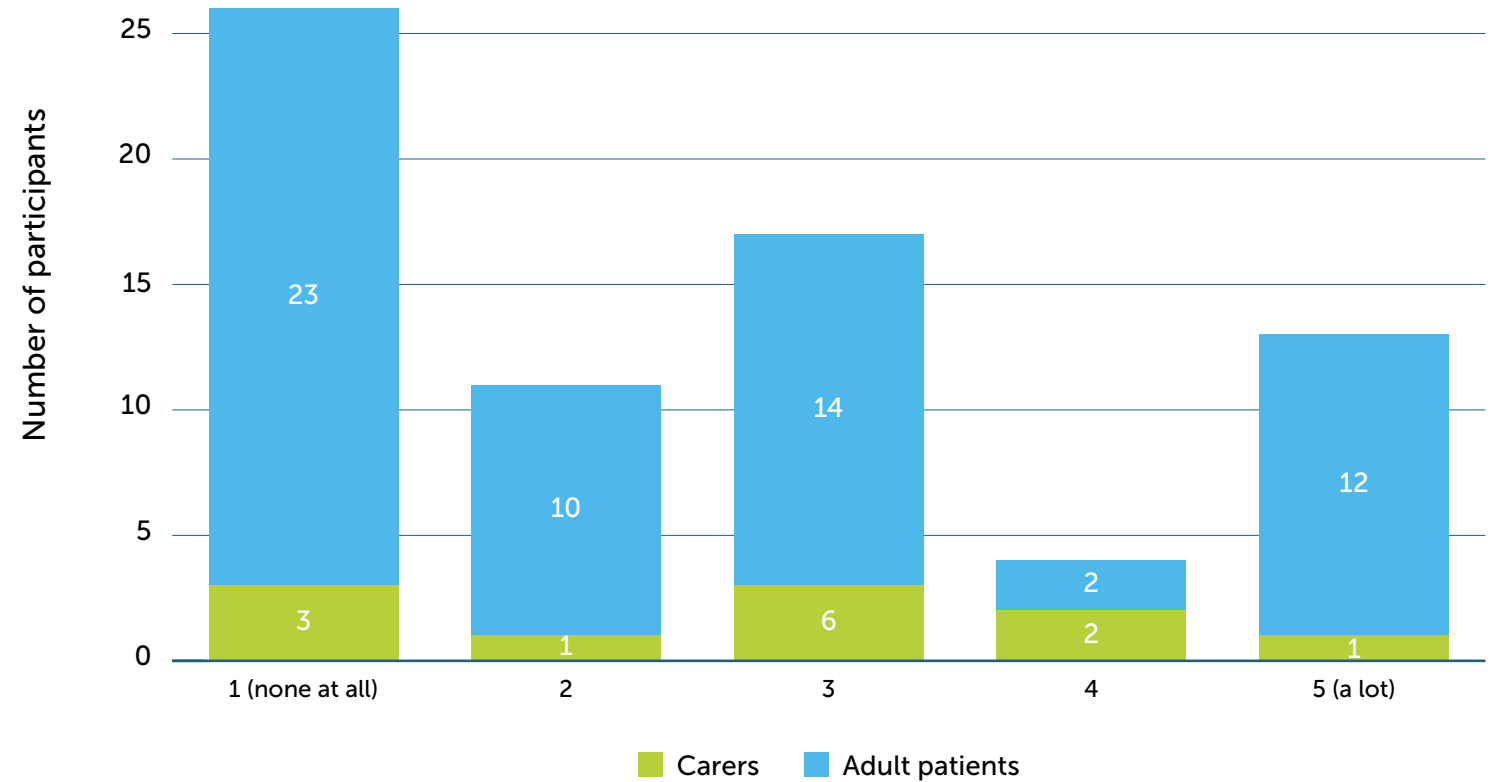

Figure 2: The proportion of patients who had to mix more than one vial of product before and after switching

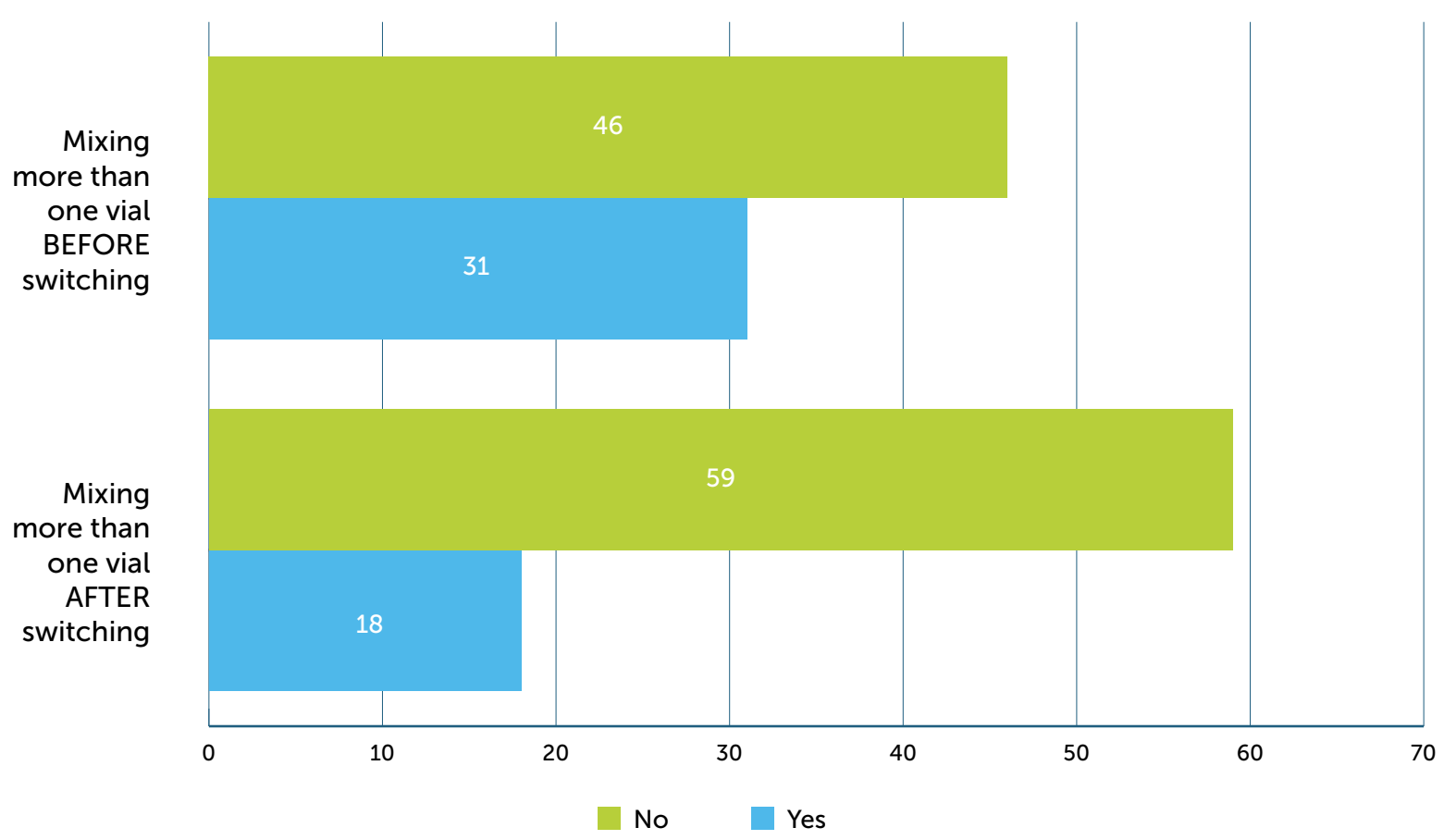


indicated that the switch had resulted in a change in home delivery arrangements.

For most participants (92\%; 70/76), the previous treatment dose was unchanged by the switch; the number of vials per prophylactic infusion was unchanged for $79 \%$ (60/76), while for $18 \%$ of patients $(14 / 76)$ it was fewer. Only two patients reported a higher number of vials per infusion; both were patients previously on very low doses of factor $\mathrm{IU} / \mathrm{kg} /$ dose.

For $88 \%$ of participants $(68 / 77)$, there was no change in the number of weekly infusions.

For $58 \%$ of participants (45/77) total preparation time was unchanged, while $33 \%$ of participants $(26 / 77)$ reported that it was shorter.

Prior to the switch, $40 \%$ of participants $(31 / 77)$ had to mix more than one vial (Figure 2); following the switch, this fell to $23 \%(18 / 77)$.

\section{Perceptions of NovoEight}

Participants were asked specific questions regarding storage temperature and transport of NovoEight. Although the product is said to be stable at temperatures up to $40^{\circ} \mathrm{C}, 73 \%$ of participants $(54 / 74)$ thought it could be stored at temperatures of up to $25^{\circ} \mathrm{C}$. Only one third of participants $(33 \% ; 26 / 77)$ said they stored it at room temperature at home; the remainder stored it in the refrigerator. However, 52\% (37/71) were happy to transport it at room temperature when travelling. This suggests that there had been no change in advice from haemophilia centres about storage of clotting factor with the introduction of the new product, as most recombinant factor VIII products have been room temperature stable for some years. Individuals with haemophilia may have adopted their own methods for storage when travelling since the introduction of recombinant products, which are considered more stable, in general, than previously used plasma-derived products; however, this was not further explored in the questionnaire.

When asked to consider packaging, the user kits and ease of infusion, responses were generally weighted in favour of being as good or better than the previous product (Figure 3).

Freely expressed views with respect to packaging, ease of mixing and infusion are summarised in Table 2. For most parameters there was a balance between positive and negative comments. Analysis of individual responses showed that those who switched from plasma-derived products were more appreciative of the reduced packaging and increased convenience associated with recombinant products. Numbers were too small for statistical analysis.

\section{Impact of NovoEight}

Some 46 participants reported trough levels following the switch to NovoEight, but 24 said these had not been tested or the results were not known. Of those reporting a trough level, $78 \%(38 / 46)$ said these had been unchanged.

Figure 3: Participants' views on packaging, user kits and ease of infusion compared with previous product

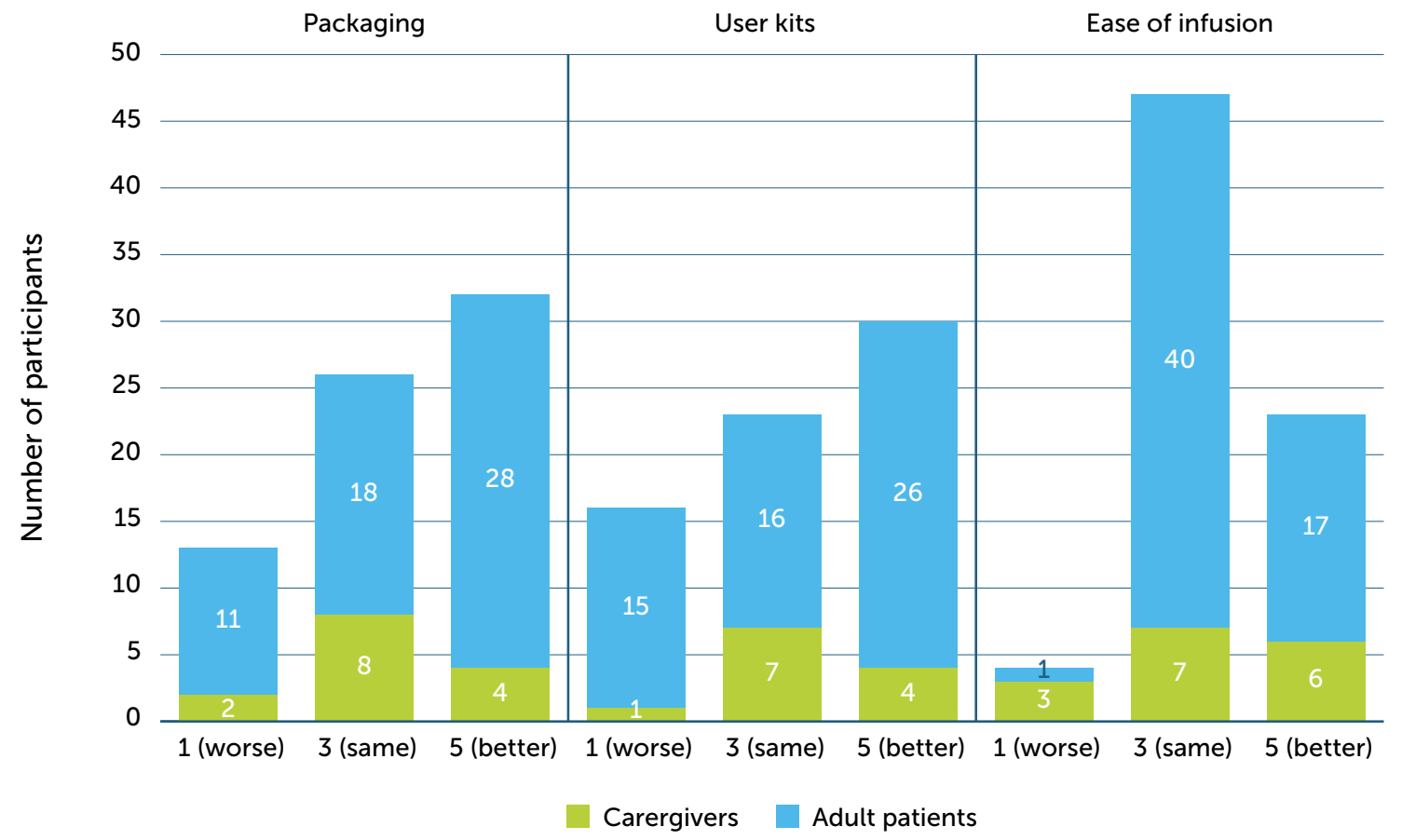




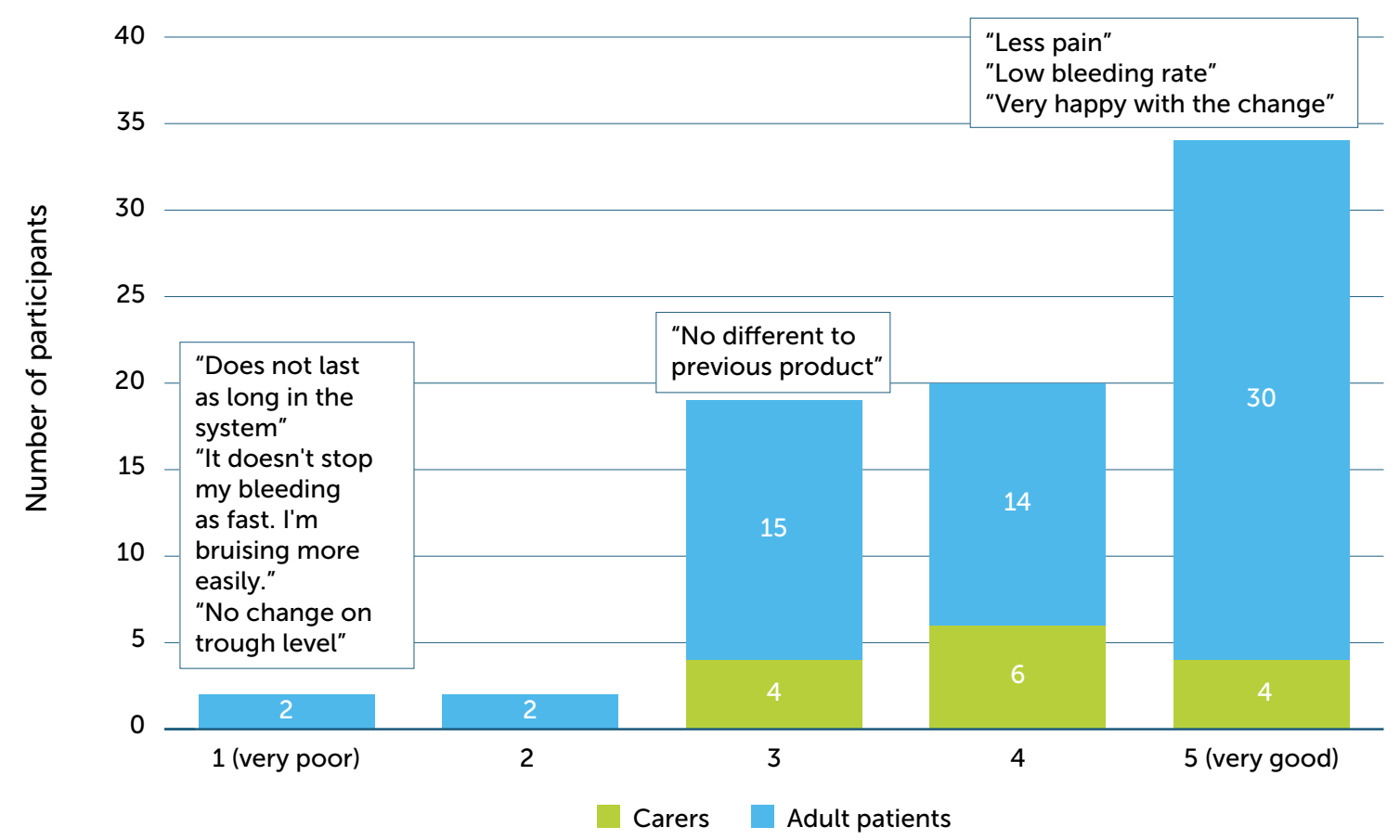

Overall, most patients $(93 \%$; 68/73) were as confident in treatment $(76 \% ; 56 / 73)$ or felt more confident $(16 \% ; 12 / 73)$. Three of these patients had previously been on a plasma-derived product and three were on products withdrawn from the market; the remainder had been on ReFacto ${ }^{\circledR}$ (Pfizer).

Among the five participants reporting worsened confidence, two also reported lower trough levels (in one case the patient was also having to mix two vials where previously he had not), and one was having more infusions each week. One participant did not view the new product very positively (he disliked the number of packages, reported a greater infusion time, and said he perceived that his trough levels were lower, although these had not been measured) and subsequently switched back to his previous product.

When asked to rate their overall opinions on NovoEight on a scale of 1 to 5 , where 1 was very poor and 5 was very good, the new product received a median score of 4 (range 1 to 5 ). Figure 4 summarises the rating scores, together with some of the reasons given.

\section{DISCUSSION}

Our results suggest that NovoEight has been generally very well received by UK users. The mean time on previous medication is the same for adults and children, confirming that the switches recorded related directly to the tender process. The range of patients' previous products is of interest: while a minority reflect the ongoing move from a plasma-derived to recombinant product or product non-availability following the tender, most switches were from one recombinant product to another, for which there was no financial incentive, suggesting that these switches were made principally to meet volume targets. Even though most patients felt they had little or no influence over the decisions to switch products, most generally accept the need to do so.

Perhaps understandably, health care commissioners determine product availability and reimbursement by focusing on medical attributes and benefits, tending not to consider factors that affect convenience to patients. For users, however, elements such as product packaging and storage requirements may be major and are a frequently overlooked element of patient acceptability and satisfaction, which is recognised to be an important determinant of adherence with treatment adherence ${ }^{[5]}$.

Poor adherence with treatment is associated with poorer outcomes in haemophilia, including spontaneous bleeding and joint damage. In higher income countries, where there is generally good access to treatment, poor adherence may reflect difficulties with treatment at home, a lack of skills for self-treatment, perceived negative consequences of treatment (for example, pain or discomfort caused by infusions) and lack of perceived benefit to symptoms [6]. It may also be influenced by the time consumed for treatments and lack of patient satisfaction with treatment devices. Surveys suggest that patients prefer simple administration kits with the fewest reconstitution steps ${ }^{[7]}$. 
Table 2: Comments on NovoEight offered by participants

\begin{tabular}{l|l|l|l} 
& POSITIVE COMMENTS & NEUTRAL COMMENTS & NEGATIVE COMMENTS \\
\hline Packaging & $\begin{array}{l}n=11 \\
\text { Smaller boxes, ease of storing }\end{array}$ & $\mathrm{n}=9$ & $\begin{array}{l}\mathrm{n}=13 \\
\text { Two boxes, takes space }\end{array}$ \\
\hline Ease of mixing & $\begin{array}{l}\mathrm{n}=8 \\
\text { Easier to mix and administer }\end{array}$ & & \\
\hline User kits & $\begin{array}{l}\mathrm{n}=6 \\
\text { Smaller, fewer resources wasted }\end{array}$ & & $\begin{array}{l}\mathrm{n}=3 \\
\text { Ordering ancillaries separately } \\
\text { is inconvenient }\end{array}$ \\
\hline Product overall & $\mathrm{n}=3$ & $\mathrm{n}=3$ \\
& No bleeds, less pain & & Concerns about half-life \\
\hline
\end{tabular}

Our study suggests that most users were happy with the packaging and accessories associated with NovoEight. When asked to consider packaging, the user kits and ease of infusion, participants generally viewed the new product more positively than their previous treatment. Where negative comments were received, these were strongly influenced by patients' previous experience of products. Recombinant products are associated with reduced infusion volumes compared with plasma-derived products, which has translated into smaller product packaging, while newer products also benefit from improvements in reconstitution and administration kits, which are generally more compact and portable.

Comments from participants indicated that those who switched from plasma-derived products were more appreciative of the reduced packaging and increased convenience associated with recombinant products, finding NovoEight to be "easier to mix and infuse" and "less to carry and overall easier to manage".

NovoEight is administered by means of pre-filled diluent syringe (MixPro ${ }^{\circledR}$ ) which has previously been evaluated among patient/carer users and nurses ${ }^{[8]}$. It was described as being user-friendly, simple and quick; its compactness and portability were highlighted as advantages for storage and travel.

NovoEight is a B-domain truncated recombinant human coagulation factor VIII for the treatment and prevention of bleeding in patients with haemophilia $A^{[9-11]}$. In a long-term stability study NovoEight was shown to remain potent after three

Table 3: Statistical analyses based on those switching from ReFacto compared with other products ( $n=73 / 77$ )

\begin{tabular}{|c|c|c|c|c|c|c|}
\hline Preparation time & Shorter & Unchanged & Greater & & & P-value \\
\hline ReFacto & 13 & 34 & 6 & & & \multirow[t]{2}{*}{0.0068} \\
\hline Non-ReFacto & 12 & 7 & 0 & & & \\
\hline Number of vials & Fewer & Unchanged & More & & & \\
\hline Refacto & 7 & 45 & 1 & & & \multirow[t]{2}{*}{0.055} \\
\hline Non-ReFacto & 7 & 11 & 0 & & & \\
\hline Trough levels & Lower & Unchanged & Higher & $\begin{array}{l}\text { Not tested/ } \\
\text { unknown }\end{array}$ & & P-value \\
\hline ReFacto & 1 & 26 & 7 & 17 & & \multirow[t]{2}{*}{0.92} \\
\hline Non-ReFacto & 0 & 9 & 3 & 7 & & \\
\hline Confidence & Better & Same & Worse & & & \\
\hline ReFacto & 6 & 44 & 3 & & & \multirow[t]{2}{*}{0.11} \\
\hline Non-ReFacto & 6 & 12 & 2 & & & \\
\hline Satisfaction rating & 1 & 2 & 3 & 4 & 5 & \\
\hline ReFacto & 1 & 2 & 15 & 14 & 21 & \multirow[t]{2}{*}{0.020} \\
\hline Non-ReFacto & 0 & 0 & 2 & 4 & 13 & \\
\hline Packaging rating & 1 & 2 & 3 & 4 & 5 & \\
\hline ReFacto & 9 & 5 & 17 & 9 & 13 & \multirow[t]{2}{*}{0.0073} \\
\hline Non-ReFacto & 0 & 1 & 5 & 2 & 11 & \\
\hline
\end{tabular}


months' exposure to temperatures of $40^{\circ} \mathrm{C}^{[12]}$. Treatment storage issues, especially the need for refrigeration, have been shown to be a common problem reported by people with haemophilia. A portability study recently found that most people with haemophilia are restricted in their personal activities, particularly travel and sports, due to temperature storage issues ${ }^{[13]}$.

NovoEight has been differentiated from other marketed products on the basis of greater ease with respect to travelling and storage. However, comments from respondents suggest that this is something that patients already take for granted:

\section{"My activities have never been affected by the storage requirements. I have always taken it everywhere." [former Helixate user]}

"I have always travelled with FVIII, it has never been a problem, including taking it to India regularly for many years." [former Kogenate user]

In the UK, many patients have had room temperature stable products for several years and this has not been seen as an issue before. For those switching from a plasma-derived product this may be perceived as an advantage, although no such comments were offered by participants in our study.

There appeared, however, to be a poor level of understanding across all participants of the specific temperature requirements for this product: very few had noted that it was stable up to a high temperature, suggesting either that this held little relevance to users or that it may not have been adequately communicated by healthcare professionals.

For most patients (78\%), confidence in treatment was unchanged by the switch. Among the 11 patients who suggested their confidence in their treatment had improved, three had previously been on a plasmaderived product and three were on products withdrawn from the market. The remainder had been on ReFacto. The perception of confidence may have been impacted by timing: the survey was conducted at a time when plasma-derived products were in the news because of the UK Infected Blood Inquiry.

Among the five participants who reported worsened confidence, four had switched from recombinant products. Two also reported lower trough levels (in one case the patient was also having to mix two vials where previously he had not due to dose change and vial sizes), and two were having more infusions each week, although it is not clear that if the new dosing regimen was due to the change in product, recent clinical change and/or PK analysis. One participant did not view the new product very positively (he disliked the number of packages and claimed a greater infusion time) and subsequently switched back to his previous product. It is interesting to note that at a reported half-life of 10.8-12 hours, NovoEight has a shorter reported halflife than either ReFacto ( $14.5 \pm 5.3$ hours) or Kogenate (13.74 hours) ${ }^{[14]}$.

Overall, however, NovoEight has been generally very well received by UK patients. Most patients appreciate the packaging and find it has increased convenience and is easy to use. Satisfaction with the new product is greater among those who switched from a plasmaderived products and products that have been removed from the market than among those who switched from established recombinant products. While a minority of patients have expressed concerns, overall, switching to the new product has not adversely impacted confidence in treatment.

\section{ACKNOWLEDGEMENTS}

The study reported in this paper was funded by Novo Nordisk.

The authors have advised no interests that might be perceived as posing a conflict or bias.

This paper reports on a survey to which participants responded knowing any comments may be reported.

\section{ORCID}

Debra Pollard (iD https://orcid.org/0000-0002-7797-3500 Mike Holland (ID https://orcid.org/0000-0002-9173-4100 Kate Khair (iD) https://orcid.org/0000-0003-2001-5958

\section{REFERENCES}

1. Srivastava A, Brewer AK, Mauser-Bunschoten EP, et al. Guidelines for the management of hemophilia. Haemophilia 2013; 19: e1-47. doi: 10.1111/j.1365-2516.2012.02909.x.

2. Hay CR. Purchasing factor concentrates in the 21st century through competitive tendering. Haemophilia 2013; 19(5): 660-7. doi: 10.1111/hae.12169.

3. NovoEight ${ }^{\circledR}$ Summary of Product Characteristics, April 2018. Available from https://www.ema.europa.eu/en/documents/ product-information/novoeight-epar-product-information_ en.pdf (accessed 27 April 2020).

4. Pollard D, Khair K, Holland M. Switching factor products: nurses' experience with NovoEight. J Haem Pract 2020; 7(1): 59-69. doi: 10.17225/jhp00156

5. Chaugule SS, Hay JW, Young G. Understanding patient preferences and willingness to pay for hemophilia therapies. Patient Prefer Adherence 2015; 9:1623-30. doi: 10.2147/PPA. S92985.

6. Remor E. Predictors of treatment difficulties and satisfaction with haemophilia therapy in adult patients. Haemophilia 2011; 17(5): e901-5. doi: 10.1111/j.1365-2516.2011.02578.x. 
7. Cimino E, Linari S, Malerba M, Halimeh S, Biondo F, Westfeld M. Patient preference and ease of use for different coagulation factor VIII reconstitution device scenarios: a cross-sectional survey in five European countries. Patient Prefer Adherence 2014; 8: 1713-20. doi: 10.2147/PPA.S64709.

8. Pollard D, Khair K, Percier C, Wong Y, Shoemark R. Evaluation of MixPro ${ }^{\oplus}$ among users and nurses. J Haem Pract 2017; 5(1): 12-23. doi: 10.17225/jhp00106

9. Kulkarni R, Karim FA, Glamocanin S, et al. Results from a large multinational clinical trial (guardian ${ }^{\mathrm{TM}} 3$ ) using prophylactic treatment with turoctocog alfa in paediatric patients with severe haemophilia A: safety, efficacy and pharmacokinetics. Haemophilia 2013; 19(5): 698-705. doi: 10.1111/hae.12165.

10. Lentz SR, Misgav M, Ozelo M, et al. Results from a large multinational clinical trial (guardian ${ }^{\mathrm{TM}} 1$ ) using prophylactic treatment with turoctocog alfa in adolescent and adult patients with severe haemophilia A: safety and efficacy. Haemophilia 2013; 19(5): 691-7. doi: 10.1111/hae.12159.

11. Lentz SR, Janic $D$, Kavakli $K$, et al. Long-term safety and efficacy of turoctocog alfa in prophylaxis and treatment of bleeding episodes in severe haemophilia A: Final results from the guardian 2 extension trial. Haemophilia 2018; 24(6): e391e394. doi: 10.1111/hae.13617.

12. Brand-Staufer B, Dahl PW, Johansen SD, Nohr AM. Turoctocog alfa is stable during storage at $40^{\circ} \mathrm{C}$ and multiple sequences of temperature cycling. Presented at WFH 2018 World Congress, Glasgow, UK, 21 May 2018.

13. Tischer B, Marino R, Napolitano M. Patient preferences in the treatment of hemophilia A: impact of storage conditions on product choice. Patient Prefer Adherence 2018; 12: 431-41. doi: 10.2147/PPA.S151812.

14. Lieuw K. Many factor VIII products available in the treatment of hemophilia A: an embarrassment of riches? J Blood Med 2017; 8: 67-73. doi: 10.2147/JBM.S103796.

HOW TO CITE THIS ARTICLE:

Pollard D, Holland M, Khair K. Experience of switching to NovoEight: views of people with haemophilia. J Haem Pract 2020; 7(1): 70-77. https://doi.org/10.17225/ihp00157

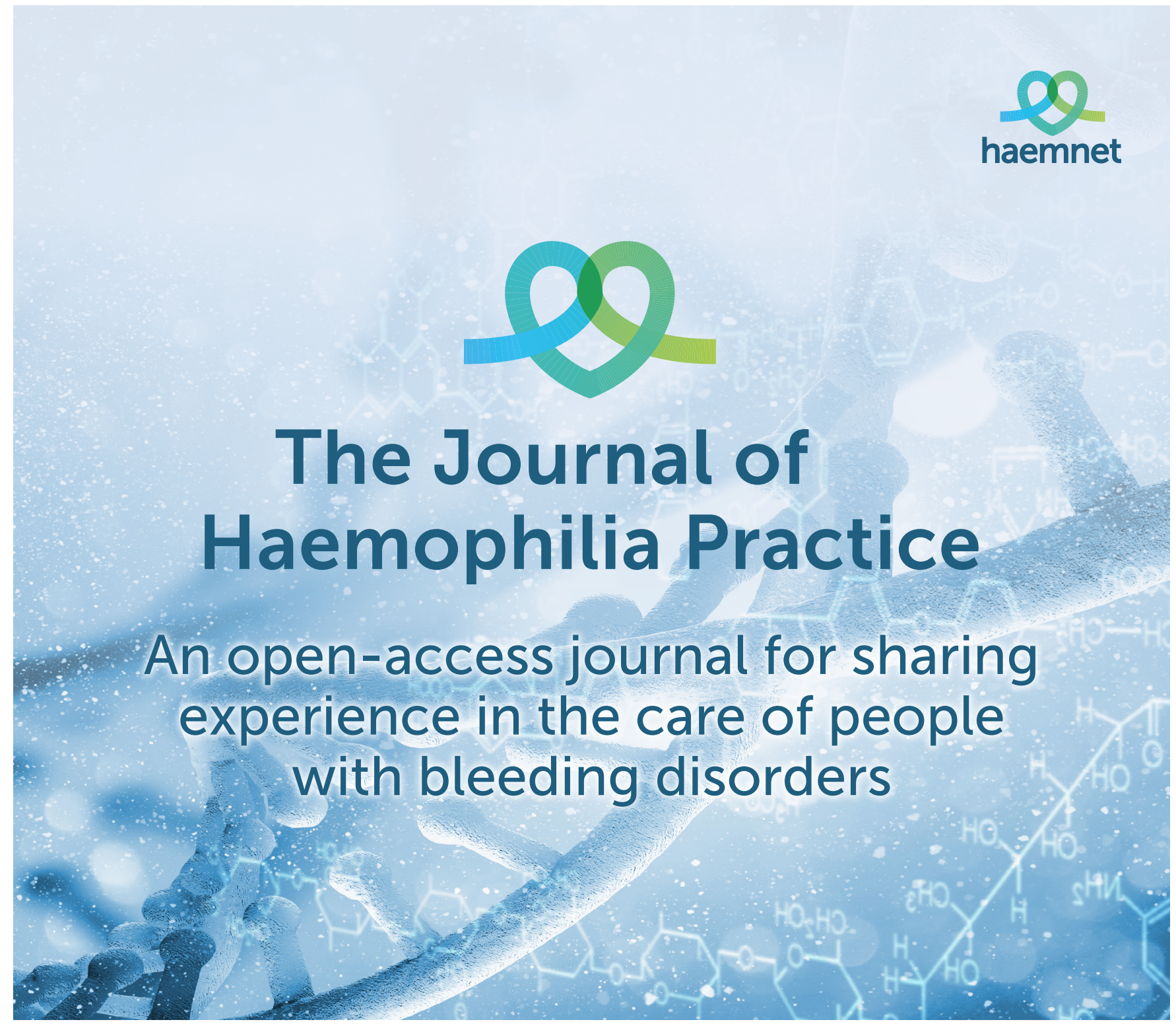

